\title{
Chemical Sensors towards Environmental Toxic Molecule Monitoring: Fluorescent Probes for Detection of Thiophenol
}

\author{
Lirong Jiang, ${ }^{a}$ Juanjuan $\mathrm{Wu},{ }^{b}$ Douyong Min, ${ }^{a}$ João Rodrigues, ${ }^{c}$ and Ruilong Sheng ${ }^{*, c}$ \\ ${ }^{a}$ College of Light Industry and Food Engineering, Guangxi University, Nanning, Guangxi 530004, China \\ ${ }^{b}$ School of Chemistry and Chemical Engineering, Tianjin University of Technology, Tianjin 300384, China \\ ${ }^{c}$ CQM-Centro de Química da Madeira, Universidade da Madeira, Campus da Penteada, \\ 9000-390 Funchal, Portugal
}

Email: ruilong.sheng@staff.uma.pt (R. S.); Tel.: +351-291705254

\begin{abstract}
Thiophenols, a family of important industrial chemicals, is highly toxic for aquatic organisms and human beings. Developing new chemical sensors with the merit of fast, low cost, portable, selective and sensitive, as well as visualizable signal output for efficient detection of thiophenols, is highly desirable. This article reviewed and discussed the current trend and statement of thiophenols-specific fluorescent probes. Moreover, the future outlook in this field was also stated.
\end{abstract}

Keywords fluorescent probes, thiophenols, toxic small molecules, environmental analysis, eco-toxicology study

Thiophenols, a family of important industrial chemicals, is utilized to produce dyes, chemical intermediates, as well as polymers. ${ }^{[1]}$ They are toxic to aquatic organisms, human beings and animals ( $\mathrm{LD}_{50} \sim 46.2 \mathrm{mg} \cdot \mathrm{kg}^{-1}$ to mouse), low dose can bring about central nervous system (CNS) injury, muscular weakness and coma, ${ }^{[2]}$ which made them highly important environmental pollutants (EPA waste code P014, environment protection agency of USA). ${ }^{[3]}$ Thus, developing efficient method for monitoring thiophenols in environmental samples and living cells is highly demanded.

To date, a number of thiophenol-specific fluorescent probes have been reported (Table 1). Most of them were designed on the basis of aromatic nucleophilic substitution reaction (thiolysis) between thiophenol and dinitrobenzenesulfonyl amides/esters attached to fluorophores, which could subsequently alter the related intramolecular charge transfer (ICT) properties and cause obvious color or fluorescence change. ${ }^{[4]}$ Various fluorescent probes were prepared with good selectivity to thiophenols against aliphatic thiols, their working (emission) wavelength covered a wide range of spectrum $(493-675 \mathrm{~nm})$. In the region of blue-green emission, firstly prepared 7-nitro-2,1,3benzoxadiazole (NBD)-based probes showed good selectivity to thiophenols with fluorescent "turn-on", but the high detection limit at millimolar level restricted its application. ${ }^{[5]}$ Comparatively, coumarin-based probes with dinitrobenzenesulfonyl amide/ ester at 3-position ${ }^{[6]}$ have lower detection limit (nanomolar level) and adjustable wavelength $(495-535 \mathrm{~nm})$. Long wavelength probes, especially near infrared (NIR) one, could minimize background fluorescence interference and benefit for noninvasive deep tissue imaging of thiophenols in vivo. ${ }^{[7]}$ Many long wavelength probes for thiolphenols are working at yellow-orange emission region (560-600 nm), few red/NIR fluorescent probes (> $610 \mathrm{~nm}$ ) have been developed. ${ }^{[8,9]}$ Recently, we one-step synthesized a NIR fluorescent probe NB-DN (675 $\mathrm{nm}$ ) to detect thiolphenols and visualize detoxification process of $\mathrm{H}_{2} \mathrm{O}_{2}$ to thiophenol in HeLa cells. ${ }^{[10]}$ Moreover, dinitrobenzene- sulfonyl ester-bearing probes possess relatively quicker responses than their dinitrobenzenesulfonyl amide counter- parts, ${ }^{[6 a, 9 b]}$ due to their faster $\mathrm{SN}_{\mathrm{Ar}}$ reaction rate. Besides, the reported probes demonstrated pseudo-first-order reaction kinetics to thiophenol in solution. ${ }^{[9,10]}$ Although the above remarkable progress was obtained, most of the reported probes still work in the mixture of buffer solution with organic solvent, and their synthetic routes are tedious and redundant. Moreover, rational design and synthesis of thiophenol-specific fluorescent probes with desired sensing properties and mechanisms are not achieved and still remain a big challenge.

The anticipated fluorescent probes for thiophenols detection should be highly selective and sensitive, fast response, with large stokes shift, visualizable color output and high quantum yield. To fulfill the optimized applicability, ${ }^{[11]}$ as a future perspective, we suggested the following issues (Scheme 1) need to be further addressed: (1) Facile, low cost, green and high efficient synthesis procedures (e.g., one-pot or multi-component reactions $)^{[12]}$ need to be developed and employed to prepare new fluorescent probes; (2) To satisfy different thiophenol analytes and further optimize the sensing efficiency, new sensing mechanisms-based (e.g., AIEE, cascade-signaling, self-immolative) probes ${ }^{[13]}$ need to be rationally designed and their molecular diversity need to be expanded; (3) Probe structure-sensing property relationships (SSPR), especially, the contribution of molecular factors (e.g., topology, linkage bonds, electrodonating/withdrawing groups (EDG/EWG), as well as flexibility/ rigidity) to the relevant sensing properties, need to be systematically studied; (4) For in vivo imaging and monitoring of thiophenols and toxicological analysis, new NIR probes $(650-800 \mathrm{~nm})$ possess low cytotoxicity, good water solubility and high cell membrane permeability, is highly demanded. Notably, in vivo NIR probes should avoid the risk of competition reaction of aliphatic biothiols (e.g., cysteine, homocysteine and glutathione) to thiophenols under enzyme catalysis in body fluid and cytoplasma; (5) For practical application, it is highly desirable to develop immobilized fluorescent probes by using functional polymers/dendrimers/nanomaterials as supporter or scavenger, through covalent or non-covalent surface modifica- 
Table 1 Several representative thiophenol-specific fluorescent probes

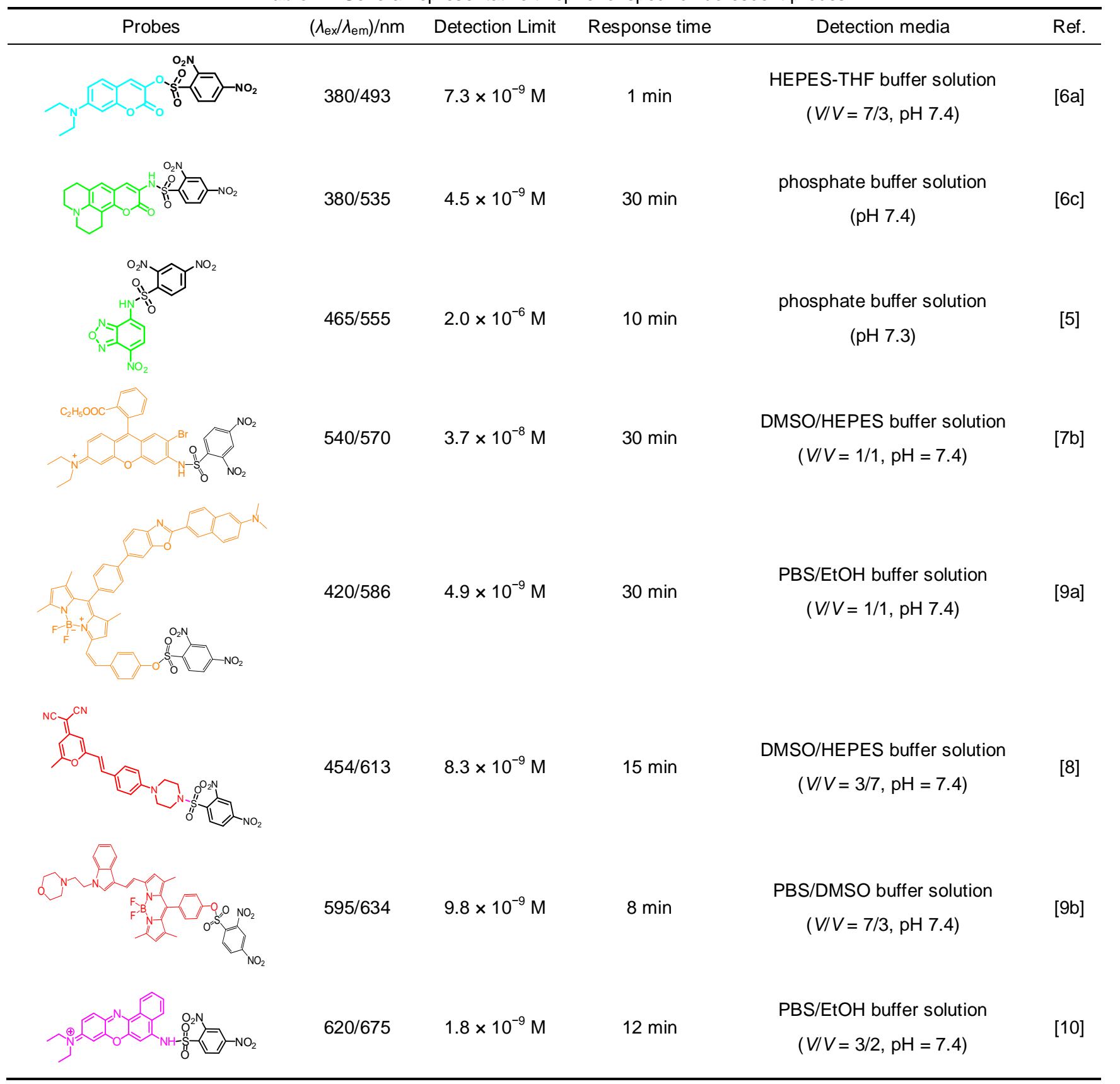

Scheme 1 Possible future directions for the R\&D of thiophenol-specific fluorescent probes

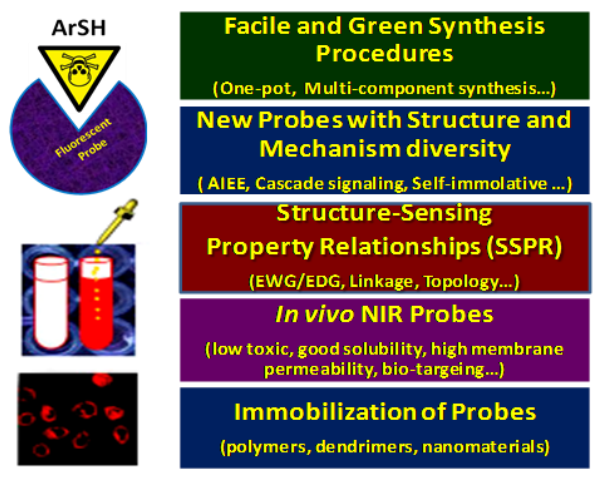

tion. ${ }^{[14]}$

We believe that, in the near future, based on the dedicated works from chemists and biochemists worldwide, more and more efficient fluorescent probes for thiophenols detection will be created, optimized and employed in the fields of environmental analysis, eco-toxicology study, and in vivo bio-imaging.

\section{Acknowledgement}

We appreciate ARDITI-Agência Regional para o Desenvolvimento da Investigação Tecnologia e Inovação, through the project M1420-01-0145-FEDER-000005-Centro de Química da Madeira-CQM+(Madeira 14-20), ARDITI-2017ISG-003, FCT-Fundação para a Ciência e a Tecnologia (project PEst-OE/QUI/UI0674/2019, CQM, Portuguese Government funds), and project PROEQUI PRAM-Reforço do Investimento em Equipamentos e Infraestruturas Científicas na RAM (M1420-01-0145-FEDER-000008). 


\section{References}

[1] (a) Lin, F.; Chun, G. J. Chin. Pharm. Sci. 1999, 8, 64; (b) Shimada, K.; Mitamura, K. J. Chromatogr. B 1994, 659, 227.

[2] (a) Amrolia, P.; Sullivan, S.; Stern, A.; Munday, R. J. Appl. Toxicol. 1989, 9, 113; (b) Heil, T. Lindsay, R. J. Environ. Sci. Health B 1989, 24, 349.

[3] Proctor, N.; Hughes, J.; Hathaway, G. Proctor and Hughes' Chemical Hazards of the Workplace, John Wiley \& Sons, 2004.

[4] (a) Yao, Z.; Ge, W.; Guo, M.; Xiao, K.; Qiao, Y.; Cao, Z.; Wu, H. Talanta 2018,185,146; (b) Wang, Z.; Han, D.; Jia, W.; Zhou, Q.; Deng, W. Anal. Chem. 2012, 84, 4915; (c) Shang, H.; Chen, H.; Tang, Y.; Ma, Y.; Lin, W. Biosens. Bioelectron. 2017, 95, 81; (d) Zhang, W.; Liu, X.; Zhang, H.; Feng, C.; Liu, C.; Yu, M.; Wei, L.; Li, Z. J. Mater. Chem. C 2015, 3, 8248; (e) Zhang, W.; Huo, F.; Liu, T.; Wen, Y.; Yin, C. Dyes Pigment. 2016, 133, 248.

[5] Jiang, W.; Fu, Q.; Fan, H.; Ho, J.; Wang, W. Angew. Chem. Int. Ed. 2007, 46, 8445.

[6] a) Wang, X.; Zhou, J.; Zhang, D.; Wang, B. Anal. Methods 2016, 8, 6916; b) Li, J.; Zhang, C.; Yang, S.; Yang, W.; Yang, G. Anal. Chem. 2014, 86, 3037; c) Sun, Q.; Yang, S.; Wu, L.; Yang, W.; Yang, G. Anal. Chem. 2016, 88, 2266

[7] (a) Guo, S.; Leng, T.; Wang, K.; Wang, C.; Shen, Y.; Zhu, W. Talanta 2018, 185, 359; (b) Wu, J.; Ye, Z.; Wu, F.; Wang, H.; Zeng, L.; Bao, G. Talanta 2018, 181, 239; (c) Pan, Y.; Ren, T.; Cheng, D.; Zeng, Z.; Yuan, L.; Zhang, X. Chem. Asian J. 2016, 11, 3575.

[8] Zhang, M.; Leng, T.; Shen, Y.; Wang, C. Analyst 2018, 143, 756.

[9] (a) Liu, H.; Zhang, X.; Zhang, J.; Wang, Q.; Hu, X.; Wang, P.; Tan,
W. Anal. Chem. 2015, 87, 8896; (b) Wang, K.; Zhao, C.; Leng, T.; Wang, C.; Lu, Y.; Shen, Y.; Zhu, W. Dyes Pigments. 2018, 151, 194; (c) Wu, F.; Wang, H.; Xu, J.; Yuan, H.; Zeng, L.; Bao, G. Sens. Actuators B. 2018, 254, 21; (d) Shao, X.; Kang, R.; Zhang, Y.; Huang, Z.; Peng, F.; Zhang, J.; Wang, Y.; Pan, F.; Zhang, W.; Zhao, W. Anal. Chem. 2015, 87, 399.

[10] Wu, J.; Su, D.; Li, W.; Xia, C.; Rodrigues, J.; Sheng, R.; Zeng, L. Talanta 2019, 201, 111.

[11] (a) Sheng, R.; Ma, J.; Wang, P.; Liu, W.; Wu, J.; Li, H.; Zhuang, X.; Zhang, H.; Wu, S. Biosens. Bioelectron. 2010, 26, 949; (b) Ye, Z.; Duan, C.; Sheng, R.; Xu, J.; Wang, H.; Zeng, L. Talanta 2018, 176, 389; c) Xu, J.; Niu, G.; Wei, X.; Lan, M.; Zeng, L.; Kinsella, J.; Sheng, R. Dyes Pigment. 2017, 139, 166.

[12] (a) Khan, R.; Ramu, A.; Pitchumani, K. Sens. Actuator B-Chem. 2018, 266, 429; (b) Müller, T.; Levi, L. Chem. Soc. Rev. 2016, 45 2825.

[13] Yan, J.; Lee, S.; Zhang, A.; Yoon, J. Chem. Soc. Rev. 2018, 47, 6900

[14] (a) Tutov, M.; Sergeev, A.; Zadorozhny, P.; Bratskaya, S.; Mironenko, Y. Sens. Actuator B-Chem. 2018, 273, 916; (b) Liu, J.; Cheng, K.; Yang, C.; Zhu, J.; Shen, C.; Zhang, X.; Yang, G. Anal. Chem. 2019, 91, 6340; (c) Abd-El-Aziz, A.; Abdelghani, A.; Wagner, B.; Bissessur, R. Macromol. Rapid Commun. 2019, 40, 1800711 .

Received August 19, 2019 Accepted September 16, 2019 